\section{Catalytic Reactive Distillation for the Esterification Process: Experimental and Simulation}

\author{
M. Mallaiah, ${ }^{a,{ }^{*}}$ K. A. Kishore, ${ }^{b}$ and G. V. Reddy ${ }^{b}$ \\ ${ }^{a}$ Department of Chemical Engineering, \\ BV Raju Institute of Technology, Narsapur, 502313, India \\ ${ }^{b}$ Department of Chemical Engineering, \\ National Institute of Technology, Warangal, 506004, India
}

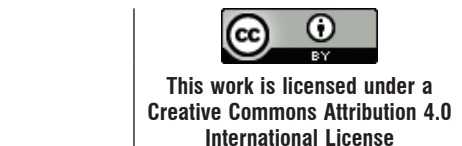

doi: 10.15255/CABEQ.2016.894

Original scientific paper Received: April 21, 2016 Accepted: July 22, 2017

In the present study, methyl acetate has been synthesized using esterification of acetic acid with methanol in a continuous packed bed catalytic reactive distillation column in the presence of novel Indion 180 ion exchange resin solid catalyst. The experiments were conducted at various operating conditions like reboiler temperature, reflux ratio, and different feed flow rates of the acetic acid and methanol. The non-ideal pseudo-homogeneous kinetic model has been developed for esterification of acetic acid with methanol in the presence of Indion 180 catalyst. The developed kinetic model was used for the simulation of the reactive distillation column for the synthesis of methyl acetate using equilibrium stage model in Aspen Plus version 7.3. The simulation results were compared with experimental results, and found that there is a good agreement between them. The sensitivity analyses were also carried out for the different parameters of bottom flow rate, feed temperatures of acetic acid and methanol, and feed flow rate of acetic acid and methanol.

Key words:

catalyst, esterification, reactive distillation, reflux ratio, mathematical model, simulation

\section{Introduction}

Reactive distillation is a process where the combination of reaction and distillation in a single unit is taking place. Reactive distillation has gained increased attention because of its high potential for process intensification. It is applicable to certain reactions where the maximum conversion is limited by chemical equilibrium in conventional reactors. It offers various advantages compared to the conventional processes of reactor followed by separation. The main advantages of reactive distillation are improved selectivity, increased conversion, better temperature control, effective utilization of reaction heat, scope for difficult separations, and the avoidance of azeotropes ${ }^{1-5}$.

The esterification of organic acid and alcohol reaction is very slow without catalyst even at higher temperatures. Addition of the catalyst generally improves the rate of reaction. The reactions could be carried out in the presence of different catalysts: homogeneous or heterogeneous. Homogeneous catalysts are mineral acids catalysts like $\mathrm{HI}, \mathrm{HCl}, \mathrm{HBr}$ and $\mathrm{H}_{2} \mathrm{SO}_{4}$. These catalysts enhance the acid-alcohol reaction to produce an ester. Heterogeneous catalysts are preferred over homogeneous catalysts due

"Corresponding author: E-mail: mmyadav2001@gmail.com; Phone: +91-9948107272; Fax: 0870 -2459547. to advantages of easy separation of the catalyst from the post reaction mixture, high selectivity for the formation of the desired product, and less corro$\operatorname{sion}^{6,7}$. Among the solid catalysts, the ion-exchange resin catalysts are used preferentially for the esterification, etherification, alkylation, metathesis reactions, and trans-esterification reactions.

Agreda et al. ${ }^{8}$ have carried experiments for the production of high purity methyl acetate in a tray reactive distillation column using sulphuric acid catalyst. The authors developed a kinetic rate expression for different concentrations of the catalyst, and that rate equation follows a nonlinear dependence of the catalyst concentration. Bessling et al. ${ }^{9}$ have published a review on the investigation of methyl acetate synthesis in a heterogeneous catalytic reactive distillation process. A method based on the interpretation of reactive distillation line diagrams was used to identify the main process parameters for the experimental investigation. For the effect of reflux ratio on the acetic acid conversion using a supported ion-exchanger in the form of Ranching rings, a heterogeneous catalyst was studied. Kreul et al. ${ }^{10}$ have carried experiments in a batch reactive distillation column using Montz structured packing in which catalyst particles were immobilized. Popken et al. ${ }^{11}$ have performed experiments for the synthesis as well as hydrolysis of 
methyl acetate using a structured catalytic packing Katapak-S in a packed bed reactive distillation. The structured packing was filled with Amberlyst 15 ion exchange resin acid catalyst. Gorak and Hoffmann ${ }^{12}$ have studied catalytic distillation using structured packings for the synthesis of methyl acetate. They have studied the characteristics of the Multipack structured packing viz., pressure drop, loading and separation efficiency conducting experiments in the reactive distillation column.

The performance of an RD is strongly influenced by the reaction kinetics. The reactions are either very fast or slow. In the case of very fast reactions, the kinetics does not play an important role, and in the case of slow reactions it is important to account the effect of reaction kinetics. The kinetics of the acetic acid with methanol to produce methyl acetate using different liquid catalyst (sulphuric acid) and solid catalysts (Indion 190 and Indion 180) was studied in our earlier work ${ }^{13-17}$. In the presence of the $\mathrm{H}_{2} \mathrm{SO}_{4}$, the concentration-based and activity-based kinetic models were developed ${ }^{13}$. The esterification of acetic acid and methanol was carried out in the presence of solid catalysts like Amberlyst 36, Indion 190, and Indion 180. PH (Ideal), PH (non-Ideal), ER and LHHW models were developed in the presence of Indion 190 by considering the adsorption effects of reactants and products on the catalyst surface ${ }^{16}$. PH (Ideal), PH (non-Ideal), ER and LHHW were developed in the presence of Amberlyst 36. A detailed reaction mechanism is proposed and discussed ${ }^{17}$ in the presence of Amberlyst 36 .

The objective of the present work was to evaluate the performance of catalytic reactive distillation column (CRD) for the synthesis of methyl acetate, and validate the results through simulation. In the present work, the kinetic model has been proposed and applied to the CRD process. The performance of the reactive distillation column under different operating parameters of reflux ratio, bottom flow rate, feed flow rate of acetic acid and methanol, feed temperatures of both reactants are studied.

\section{Experimental}

\section{Experimental setup}

The schematic laboratory experimental setup of Reactive Distillation Column (RDC) is shown in Fig. 1. The total height of the glass column is 3 meters and the inner diameter is $50 \mathrm{~mm}$. The reboiler has 3 liters capacity. The reboiler is equipped with an external electrical heater with $2 \mathrm{~kW}$ capacity. Reactive distillation column consists of three different zones, rectifying zone at the top, reactive zone in the middle, and stripping zone at the bottom. The nonreactive rectifying and stripping zones are packed with Hyflux (Evergreen, India, Ltd.). The middle reactive zone is packed with structured packing equivalent of Katapak-S. The desired amount of catalyst is filled in the packing elements and transferred to the column. Pt-100 temperature sensors are provided at different locations of the column and in the reboiler. All the Pt-100 sensors are connected to a digital main control board. Asbestos rope is used as insulate to reduce the heat losses. A Dean and stark type arrangement is provided at the top of the column as condenser and separator. Peristaltic pumps are used to supply the feeds to the column. The rotameters are used to measure the feed flow rates.

\section{Experimental procedure}

To start the experiment, the reboiler was filled with methanol up to 2.7 liters so that there was about $30-40 \%$ free vapor space available. Then the heater was switched on. As the reboiler started heating, the vapors of methanol from the reboiler started filling the sections one after another, and finally reached the Dean and Stark condenser, where the condensed distillate started collecting. When the temperatures along the column height reached constant values, the reflux was started by adjusting its valve. The peristaltic pumps were then started to feed methanol and acetic acid at desired flow rates, and the bottoms and distillate flow rates were started. After the column reached steady state, the samples from all sampling points, bottom, and distillate were collected at regular time intervals. Simultaneously, the temperatures along the column were recorded. The samples were analyzed for their composition. This was done by both GC and titration initially. The material balance was verified to ensure that the mass flow rate in equaled the mass flow rate out of the reactive distillation column. An indication of steady state was when the amount of the mass entering into the column equaled the amount of the mass leaving the distillate and bottoms. The samples from the distillate and bottoms were collected and weighed accurately with an accuracy of $\pm 0.1 \mathrm{~g}$ error. In each run, the RDC ran for 1 to 2 hours at steady state to collect sufficient data. At steady state, the temperature and composition profiles were the same with time in addition to steady state mass flow rates.

\section{Analysis}

The samples were analyzed using gas chromatograph (GC-2014 ATF, Schimadzu, Japan) equipped with a thermal conductivity detector, and Porapak-Q ( $2 \mathrm{~m}$ length and $3.17 \mathrm{~mm}$ id) packed column. High purity hydrogen gas was used as carrier gas at 


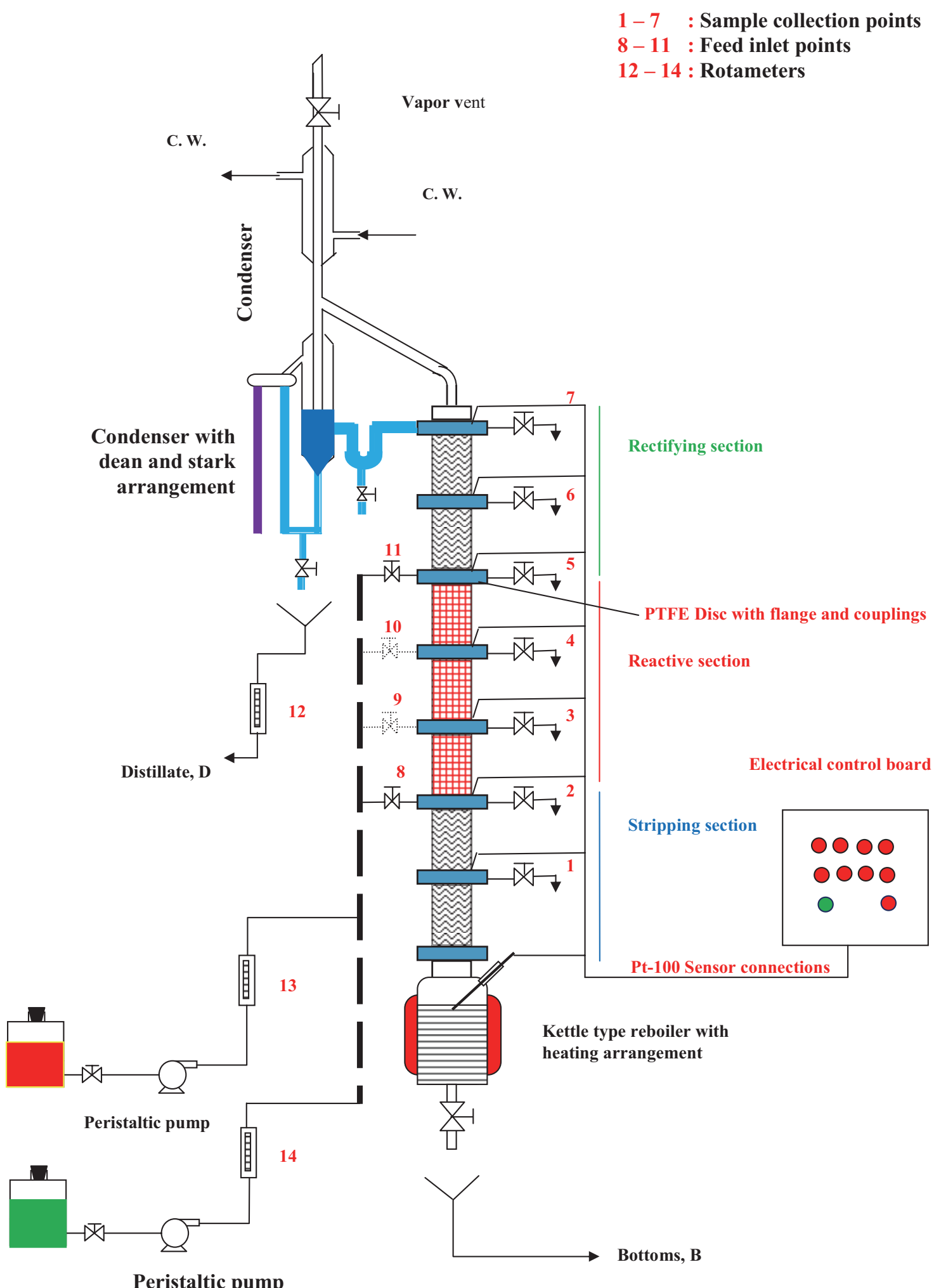

Fig. 1 - Schematic of continuous reactive distillation column 


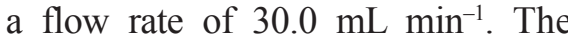
oven temperature was programmed at $323.15 \mathrm{~K}$ for $1 \mathrm{~min}$, and then raised from an initial value of $323.15 \mathrm{~K}$ to $443.15 \mathrm{~K}$ at a ramp rate of $10 \mathrm{~K} \mathrm{~min}^{-1}$ and held at $443.15 \mathrm{~K}$ for $2 \mathrm{~min}$. The detector temperature was maintained at $473.15 \mathrm{~K}$.

\section{Development of kinetic model}

The kinetic rate equation was obtained by conducting the experiments in a batch reactor under different operating conditions of reaction temperature, catalyst loading, agitation speed and size of the catalyst particles. The experimental setup and procedure are given in our earlier study ${ }^{14}$.

The adsorption and swelling experiments for esterification of acetic acid and methanol in the presence of Indion 190 and Indion 180 were investigated in our earlier study ${ }^{14-16}$. It was observed that, there was only less than $10 \%$ swelling and adsorption of the reactants, and products were very low. All the models predict the conversion of acetic acid well with experimental data under 5 $\%$ error. Hence, the $\mathrm{PH}$ non-ideal model was developed for the present

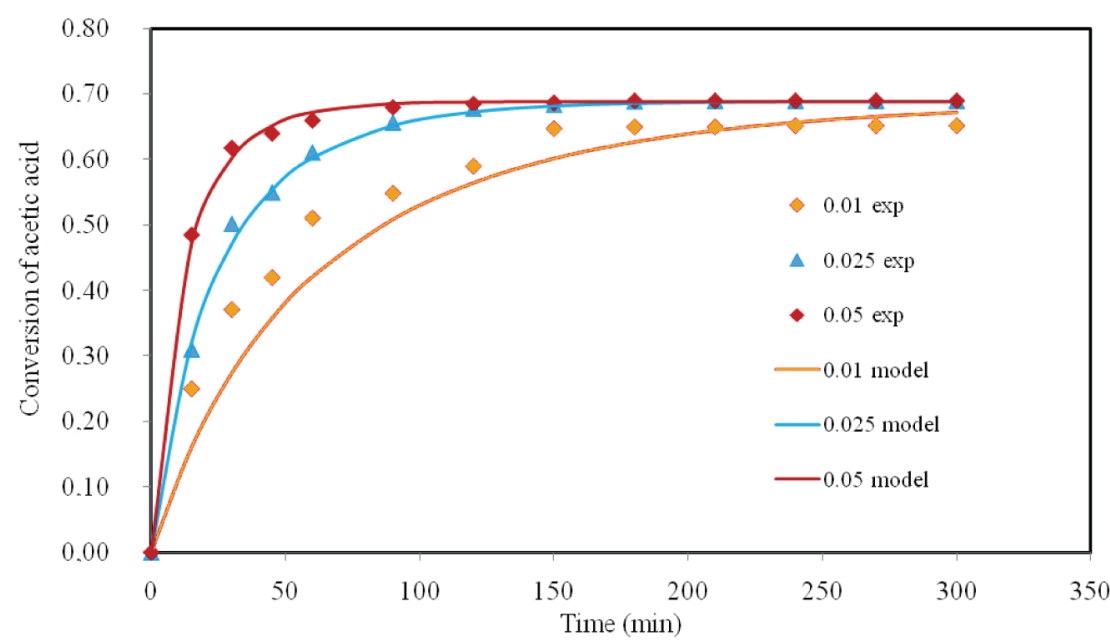

Fig. 2 - Conversion of acetic acid with time at a temperature of $343 \mathrm{~K}$ and at different catalyst loadings

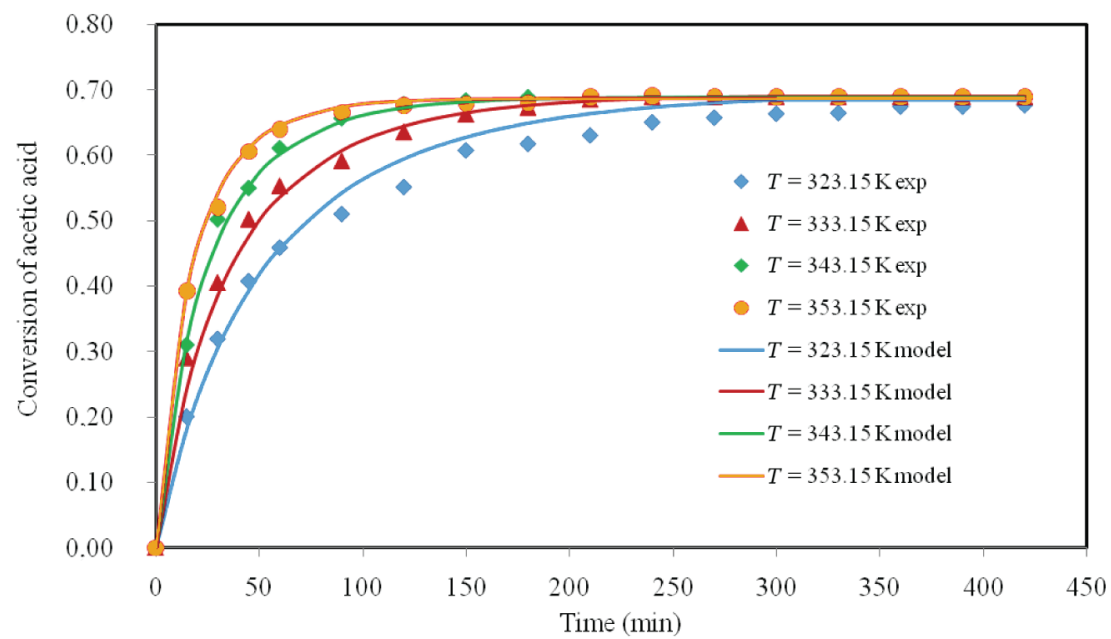

Fig. 3 - Conversion of acetic acid with time at a catalyst loading of $0.025 \mathrm{~g} \mathrm{~mL}^{-1}$ and at different reaction temperatures system in the presence of Indion 180 , which is the new kinetic model.

The pseudo-homogeneous kinetic model was developed for the esterification of acetic acid and methanol. The non-ideal pseudo-homogeneous kinetic rate equation is given by Eq. (1).

$$
-r_{i}=\frac{1}{v_{i}} \frac{1}{m_{\text {cat }}} \frac{\mathrm{d} n_{i}}{\mathrm{~d} t}=k_{f} a_{A} a_{B}-k_{b} a_{C} a_{D}
$$

The kinetic rate equation is integrated by using Runge-Kutta $4^{\text {th }}$ order method using ODE-45 MATLAB program. The kinetic parameters were fitted to the experimental data by minimizing the mean squared deviation between the experimental and calculated conversions of acetic acid. Four adjustable parameters, frequency factors $\left(k_{\mathrm{f} 0}\right.$ and $\left.k_{\mathrm{b} 0}\right)$, and activation energies $\left(E_{\mathrm{f}}\right.$ and $\left.E_{\mathrm{b}}\right)$ were fitted to the pseudo-homogeneous kinetic equation.

The calculated conversions of the acetic acid compared with the experimental values to find the mean relative error $\left(F_{r e l}\right)$ and the mean squared de- viation $\left(F_{a b s}\right)$ are given below. The maximum allowable error to find the constants was $5 \%$.

The mean relative errors of conversion of acetic acid of experimental and calculated from the model were found.

$$
F_{r e l}=\sum^{n_{s}} \frac{\left|X_{\text {aceticacidexp }}-X_{\text {aceticacidcal }}\right|}{n_{s}}
$$

The squared differences of conversion of acetic acid of experimental and calculated from the model were found.

$$
F_{a b s}=\sum^{n_{s}} \frac{\left(X_{\text {aceticacidexp }}-X_{\text {aceticacidal }}\right)^{2}}{n_{s}}
$$

Fig. 2 shows the conversion kinetics of the acetic acid at different catalyst loadings of Indion 180. The other conditions are temperature: $343 \mathrm{~K}$, catalyst size: 725 microns, agitation speed: $240 \mathrm{rpm}$. The figure suggests that the model predictions are 
Table 1 -Kinetic parameters for the pseudo-homogeneous (UNIQUAC) model

\begin{tabular}{c|c|c|c|c|c|c}
\hline Model & $k_{\mathrm{f} 0}$ & $E_{\mathrm{f}}$ & $k_{\mathrm{b} 0}$ & $E_{\mathrm{b}}$ & $\left(F_{r e l}\right)$ & $\left(F_{a b s}\right)$ \\
\hline Pseudo-homogeneous (UNIQUAC) model & 3479 & 35940 & 715 & 40199 & $4.95 \%$ \\
\hline
\end{tabular}

in good agreement with the experimental data. Fig. 3 shows the conversion kinetics of the acetic acid at different temperatures. The other conditions are catalyst loading: $0.025 \mathrm{~g} \mathrm{~mL}^{-1}$, catalyst size: $725 \mathrm{mi}-$ crons, agitation speed: $240 \mathrm{rpm}$. The figure suggests a close agreement between the experimental and model predictions. It also suggests that the effect of the agitation speed and size of the catalyst particles on the conversion of acetic acid is not significant. These results were compared with the literature results; where for the ion exchange resin catalysts, the agitation speed and catalyst size effect on the conversion of acetic acid is negligible ${ }^{14}$. Hence, this developed kinetic equation was used in the equilibrium stage model of the reactive distillation column. The kinetic parameters for the $\mathrm{PH}$ model are given in Table 1.

\section{Equilibrium stage model for reactive distillation}

The mathematical equations describing the steady state equilibrium stage process are given below ${ }^{18}$.

Total Condenser

Molar component balance

$$
\left(v_{2} y_{i, 2}-\left(d+l_{1}\right) x_{i, 1}\right)=0
$$

Total energy balance

$$
\left(v_{2} h_{2}^{v}-\left(d+l_{1}\right) h_{1}^{l}-q_{C}\right)=0
$$

Summation

$$
\sum_{i=1}^{N C} x_{i, 1}=1
$$

Reboiler

Molar component balance

$$
\left(l_{N-1} x_{i, N-1}-v_{N} y_{i, N}-l_{N} x_{i, N}\right)=0
$$

Total energy balance

$$
\left(l_{N-1} h_{N-1}^{l}-v_{N} h_{N}^{v}-l_{N} h_{N}^{l}+q_{R}\right)=0
$$

Summation

$$
\begin{aligned}
& \sum_{i=1}^{N C} x_{i, N}=1 \\
& \sum_{i=1}^{N C} y_{i, N}=1
\end{aligned}
$$

Vapour-liquid equilibrium

$$
y_{i, N}=\frac{p^{\text {sat }}{ }_{i, N}}{p_{\text {total }}} x_{i, N}
$$

For $\mathrm{j}^{\text {th }}$ stage

Molar component balances

$\left(l_{j-1} x_{i, j-1}-v_{j+1} y_{i, j+1}-l_{j} x_{i, j}-v_{j} y_{i, j}+\varepsilon_{j} r x n_{i, j}\right)=0$

For feed stage

$$
\left(\begin{array}{l}
l_{j-1} x_{i, j-1}+v_{j+1} y_{i, j+1}+f_{j} z_{i, j}^{F}- \\
-l_{j} x_{i, j}-v_{j} y_{i, j}+\varepsilon_{j} r x n_{i, j}
\end{array}\right)=0
$$

Total energy balance

$$
\left(l_{j-1} h_{j-1}^{l}+v_{j+1} h_{j+1}^{v}-l_{j} h_{j}^{l}-v_{j} h_{j}^{v}\right)=0
$$

For feed stage

$$
\left(l_{j-1} h_{j-1}^{l}+v_{j+1} h_{j+1}^{v}+f_{j} h_{j}^{f}-l_{j} h_{j}^{l}-v_{j} h_{j}^{v}\right)=0
$$

Summation

$$
\begin{aligned}
& \sum_{i=1}^{N C} x_{i, j}=1 \\
& \sum_{i=1}^{N C} y_{i, j}=1
\end{aligned}
$$

Vapour liquid equilibrium

$$
y_{i, j}=\frac{p^{\text {sat }}{ }_{i, j}}{p_{\text {total }}} x_{i, j}
$$

The simulation using Eqs. (4) - (18), with the equipment parameters pertaining to our reactive distillation column, was conducted with a Radfrac of Aspen plus version 7.3. The pseudo-homogeneous kinetic equation used in the simulation has been developed from experimental data obtained in our laboratory. The UNIQUAC equation was used in Aspen plus simulations to account for the non-ideal behavior of the mixture. For the reactive packing, HETP was $100 \mathrm{~mm}$, for non-reactive packing it was $110 \mathrm{~mm}$. There were a total of 30 stages, including the condenser and reboiler.

\section{Results and discussions}

\section{Experimental results}

The experiments were carried out in the reactive distillation column at atmospheric pressure for the esterification of acetic acid with methanol to 
Table 2 -Reactive distillation column specifications

\begin{tabular}{lc}
\hline \multicolumn{1}{c|}{ Specification } & Value \\
\hline Column diameter & $50 \mathrm{~mm}$ \\
Column height & $3 \mathrm{~m}$ \\
Number of stages in the rectifying section & 9 \\
Number of stages in the reactive section & 10 \\
Number of stages in the stripping section & 9 \\
$\begin{array}{l}\text { Column operating pressure } \\
\begin{array}{l}\text { Total number of stages including reboiler and } \\
\text { condenser }\end{array}\end{array}$ \\
\hline
\end{tabular}

produce methyl acetate and water ${ }^{19}$. The total catalyst loading filled in the reactive zone was 60 grams per meter of the column and the catalyst amount was distributed uniformly in all the packing elements.

The reactive distillation column specifications are shown in Table 2. All the experimental runs were conducted to study the composition profiles of the acetic acid, methanol, methyl acetate, and water with respect to time and position along the column, as shown in Fig. 1.

The conversion of acetic acid was calculated from the molar flow rates of the bottom product that contained acetic acid to the molar flow rate of feed with pure acetic acid.

The conversion of acetic acid is given by Eq. (19)

$$
X_{A}=1-\frac{\left(w x_{A w}+d x_{A d}\right)}{f_{A} x_{A f}}
$$

where $x_{A w}, x_{A d}, x_{A f}, w, d$ and $f_{A}$ are the mole fractions of the acetic acid in the bottoms, in the distillate, in the acetic acid feed stream, bottom molar flow rate, distillate flow rate and feed molar flow rate of acetic acid, respectively.

\section{Modelling and simulation}

The modelling of RD has been considered an important task over the past years. An excellent review on modelling and simulation of reactive distillation presented by Taylor and Krishna ${ }^{1}$. In the present work, an equilibrium stage modelling was used for the simulation of reactive distillation for the methyl acetate synthesis, and compared with the experimental results. The equipment parameters used in the simulation pertain to reactive distillation column of our laboratory. Apart from steady-state mass and energy balance equations presented in the model development, the non-ideal PH kinetic rate equation developed for esterification of acetic acid with methanol was used in the simulation. Acetic acid feed was located at stage 11. Methanol feed was lo-

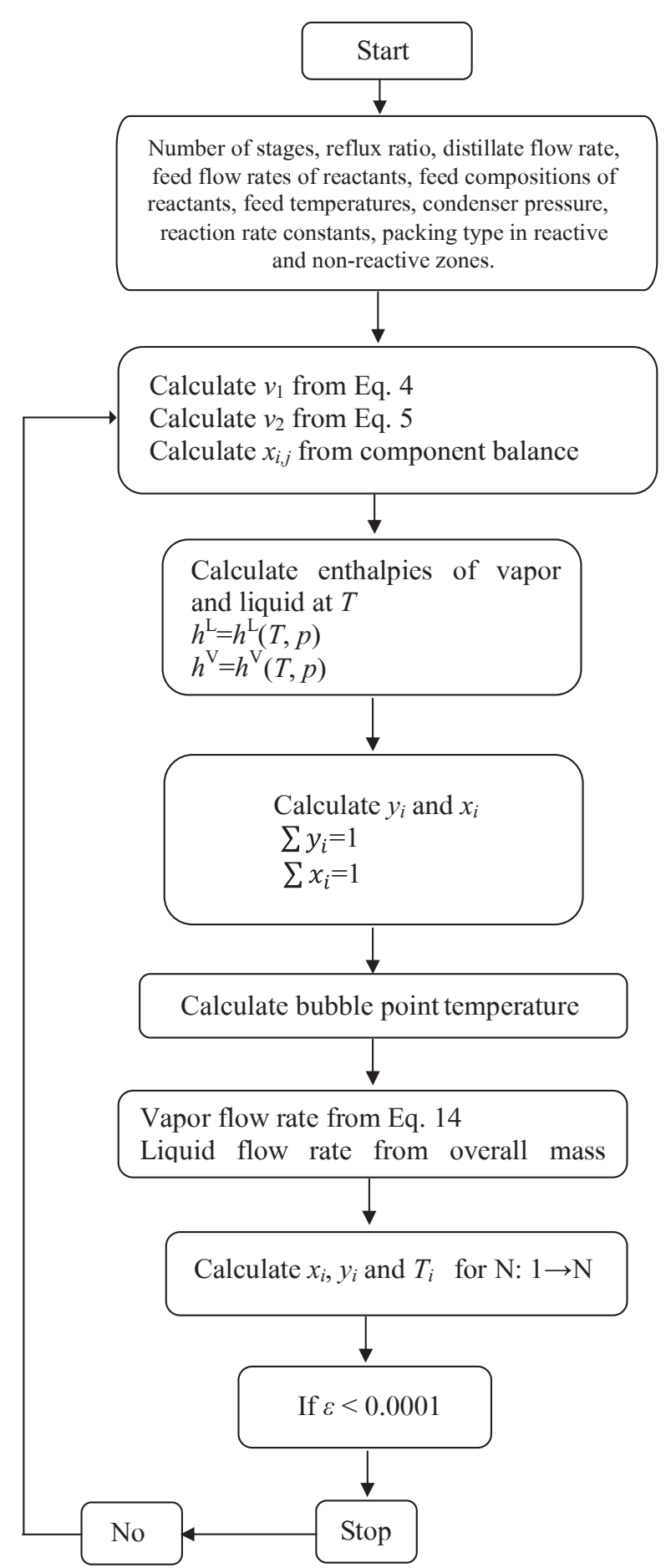

Fig. 4 - Flow chart for the algorithm of the equilibrium stage model

cated at stage 20. For simulation, the Radfrac of Aspen plus 7.3 was used. The stages were counted starting from condenser to reboiler.

A detailed step-by-step calculation procedure for solving of the equilibrium stage model equations is shown in Fig. 4. An indication of steady state is when the compositions, temperatures, and flow rates of the liquid and vapour are almost the same for a given error condition. 


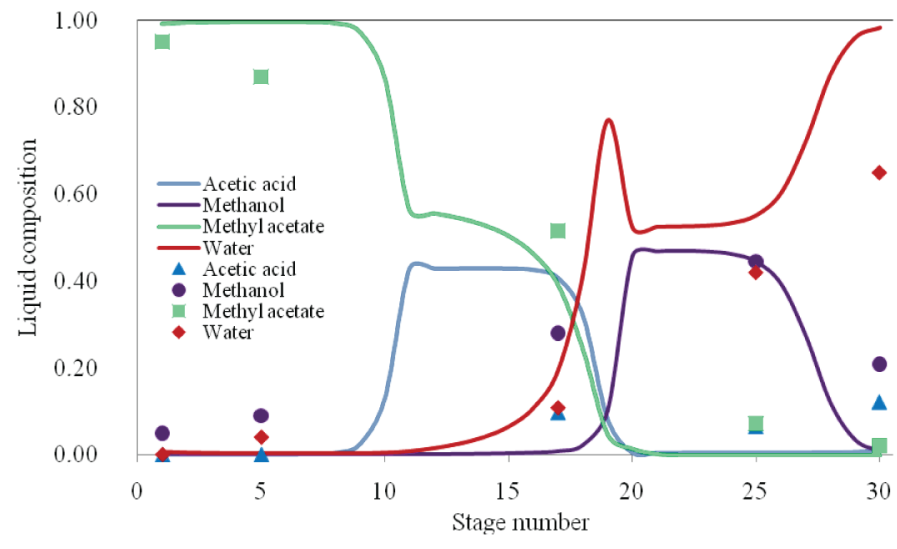

Fig. 5 - Liquid composition profiles versus stage number. Solid lines represent the simulation results from equilibrium stage model, and symbols represent the experimental data ${ }^{19}$.

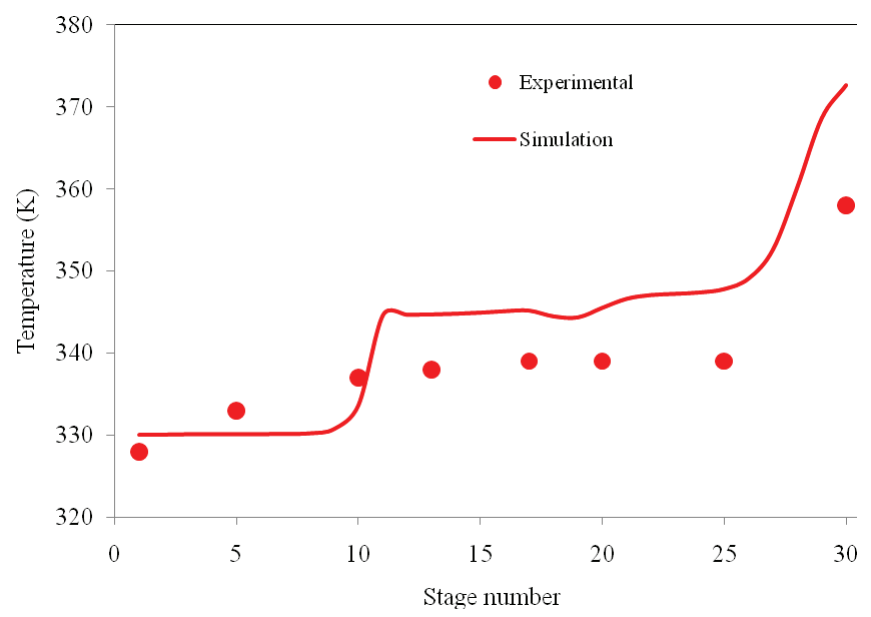

Fig. 6 - Temperature profile versus stage number. Solid line represents the simulation results from equilibrium stage model, and symbols represent the experimental data ${ }^{19}$.

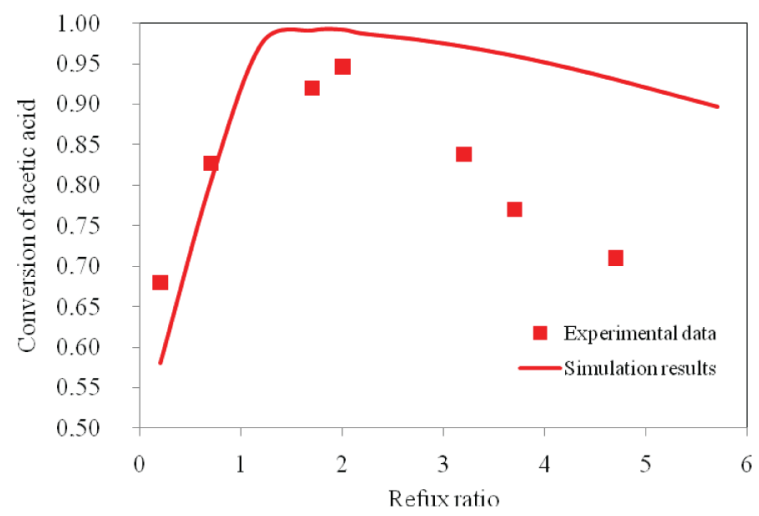

Fig. 7 - Conversion of acetic acid versus reflux ratio. Solid line represents the simulation results from equilibrium stage model, and symbols represent the experimental data.

Fig. 5 shows the comparison of the liquid composition profiles along with experimental results for the production of methyl acetate by reaction of acetic acid with pure methanol in catalytic reactive dis- tillation column. There are three different zones in the column, i.e., the rectifying zone at stages $1-10$; reactive zone at stages 11-20; and stripping zone at stages $21-30$. Fig. 5 suggests that the simulation results are closely match the experimental results for all the zones, i.e., from the top to the bottom of the reactive distillation column. From the experimental study, it was found that $95 \%$ of the methyl acetate had formed, which was close to the simulation result, whereas in the bottoms, water made up $69 \%$ of the composition, which is a greater deviation compared to the simulation results. The reason for this is that some of the un-reacted acetic acid and methanol were reported to the bottoms. Overall, the simulation results and model predictions were in good agreement with each other for all the components. Acetic acid was present only in the reactive section, indicating that more reaction is possible with methanol. Methyl acetate and water had formed as distillates and bottoms, respectively.

Fig. 6 shows the comparison of experimental and simulation results of the reactive distillation column temperature profile for the production of the methyl acetate from the condenser stage to the reboiler stage. Temperature gradually falls from reboiler to the reactive zone. In the reactive zone, the temperature remains constant. There was a sudden drop in temperature from reactive zone to rectifying zone. However, within rectifying zone, the temperature remained constant. The equilibrium stage model was able to predict the experimental data with reasonable accuracy.

In the reactive distillation process, the reflux ratio has more effect on the conversion of acetic acid. Fig. 7 shows the effect of reflux ratio on the conversion of acetic acid. The acetic acid conversion reached maximum at a reflux ratio of about 2 , and after that it gradually decreased when the reflux ratio increased. From Fig. 7, it could be observed that the experimental and model predictions are in good agreement, so equilibrium stage wise model was justified for the simulation of the reactive distillation process for the present esterification system.

\section{Sensitivity analyses}

The sensitivity analyses of the methyl acetate purity and acetic conversion were carried out for bottom flow rates; acetic acid and methanol feed temperatures and feed flow rates. The effect of the bottom flow rate, feed temperatures, and flow rates were discussed on the acetic acid conversion as well as purity of methyl acetate.

Fig. 8 shows the effect of the bottom flow rate on the purity of the methyl acetate and conversion of the acetic acid. When the bottom flow rate is in- 


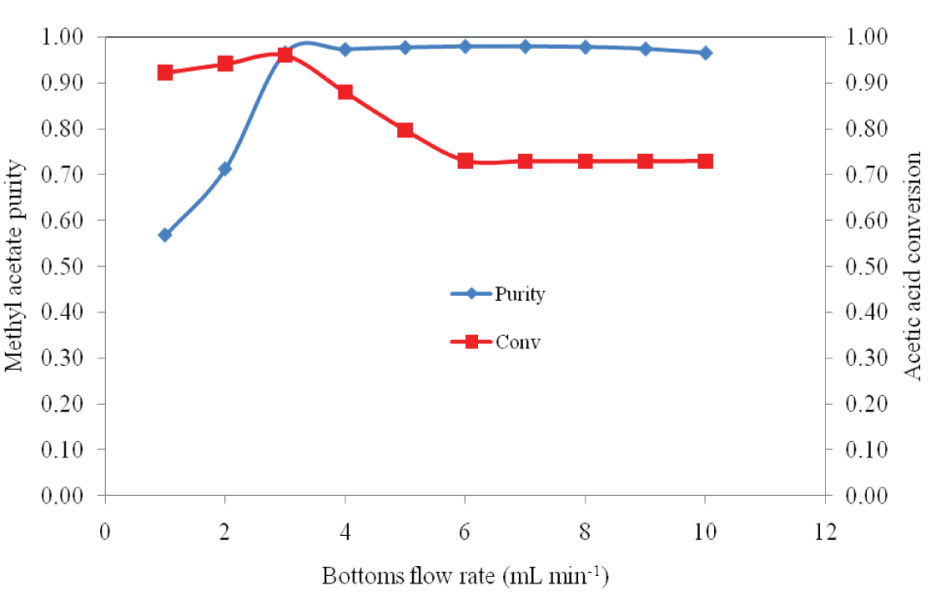

Fig. 8 - Effect of bottom flow rate on the methyl acetate purity and acetic acid conversion

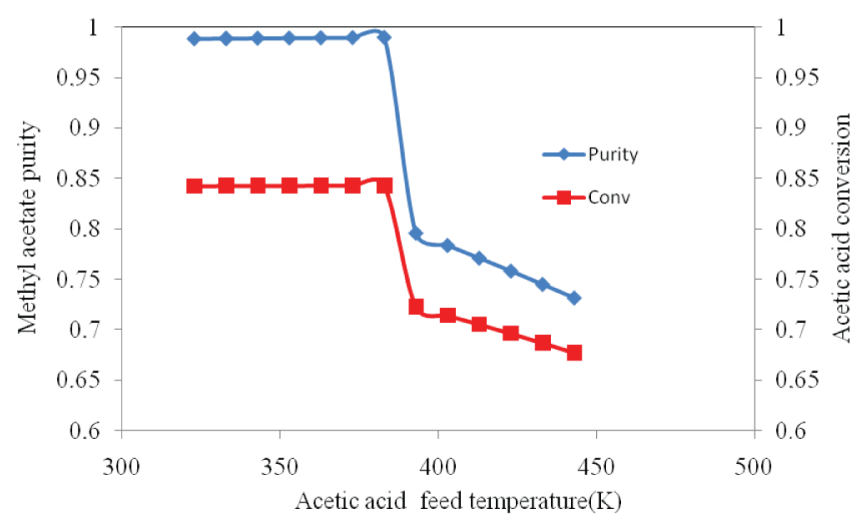

Fig. 9 - Effect of acetic acid feed temperature on the methyl acetate purity and acetic acid conversion

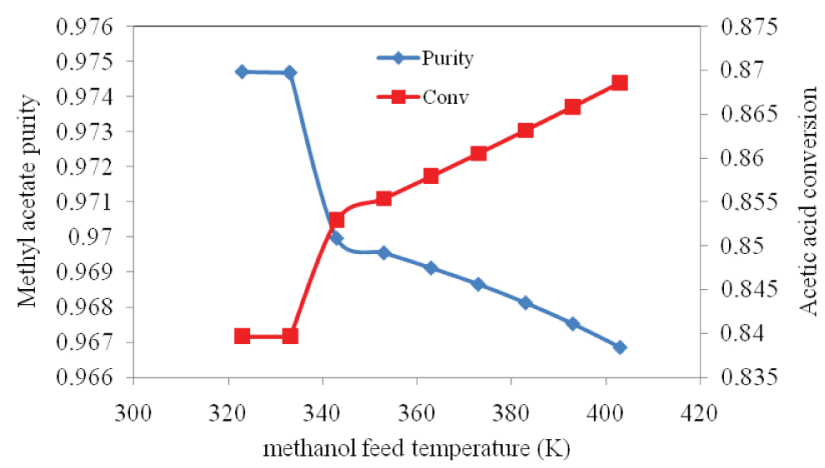

Fig. 10 - Effect of methanol feed temperature on the methyl acetate purity and acetic acid conversion

creased, the conversion of acetic acid and purity of methyl acetate increased up to $3.5 \mathrm{~mL} \mathrm{~min}^{-1}$, beyond this flow rate the acetic acid conversion and purity of the methyl acetate decreased due to decrease in distillate flow rate. The increase in bottom flow rate caused less reboiler level, and hence the rate of vaporization was not uniform. When the bottom flow rate was low, the reboiler level increased and the rate of vaporization of the reboiler solution was very low. Hence, an optimum bottom flow rate of $3.5 \mathrm{~mL} \mathrm{~min}^{-1}$ gives the maximum conversion of acetic acid and purity of distillate.

Fig. 9 shows the purity of methyl acetate and conversion of acetic acid at various acetic acid feed temperatures. As the acetic acid feed temperature increased from $320 \mathrm{~K}$ to $390 \mathrm{~K}$, the methyl acetate purity as well as conversion of acetic acid were almost the same. When the temperature was above $390 \mathrm{~K}$, there was a sudden drop in purity as well as acetic acid conversion. This was due to the formation of acetic acid from liquid state to vapor state. The esterification reaction took place in the liquid phase only. Thus, when the acetic acid feed temperature increased, it formed more vapor and the methanol was also in vapor state by absorbing the heat from the reboiler. When both reactants are in vapor state, the reaction rate was lower, so the conversion of acetic acid and purity of the methyl acetate decreased.

Fig. 10 shows the purity of methyl acetate versus methanol feed temperature and acetic acid conversion versus methanol feed temperature. When the methanol feed temperature increased from $320 \mathrm{~K}$ to $338 \mathrm{~K}$, the methyl acetate purity as well as conversion of acetic acid were almost the same. When the temperature was above $338 \mathrm{~K}$, there was a sudden drop in purity but acetic acid conversion increased. This was because most of the methanol was in vapor state, so that escaped from the reactive zone and moved upward in the column. The composition of methanol increased in distillate; hence, methyl acetate composition decreased. However, the conversion increased because acetic acid reacted with methanol in the reactive zone. Thus, the vapor(methanol) and liquid(acetic acid) formed a counter current flow, which caused more driving force for mass transfer.

Fig. 11 shows the effect of acetic acid feed flow rate on the methyl acetate purity and acetic acid conversion. When the acetic acid flow rate increased from $4.5 \mathrm{~mL} \mathrm{~min}{ }^{-1}$ to $8.9 \mathrm{~mL} \mathrm{~min}^{-1}$, methyl acetate purity increased and acetic acid conversion was almost constant. Beyond $8.9 \mathrm{~mL} \mathrm{~min}^{-1}$, further increase in flow rate caused a decrease in conversion but methyl acetate purity remained almost constant. The main reason being that the excess methanol caused high conversion and purity in the interval of feed flow rate of $4.5 \mathrm{~mL} \mathrm{~min}^{-1}$ to $8.9 \mathrm{~mL} \mathrm{~min}$, and beyond $8.9 \mathrm{~mL} \mathrm{m^{-1 }}$ acetic acid concentration was higher. Thus, un-reacted acetic acid formed in the reboiler. The conversion is dropped.

Fig. 12 shows the effect of methanol feed flow rate on the methyl acetate purity and acetic acid conversion. When the methanol flow rate increased from $5 \mathrm{~mL} \mathrm{~min}{ }^{-1}$ to $8.5 \mathrm{~mL} \mathrm{~min}^{-1}$ the methyl acetate purity slightly decreased and acetic acid conversion 


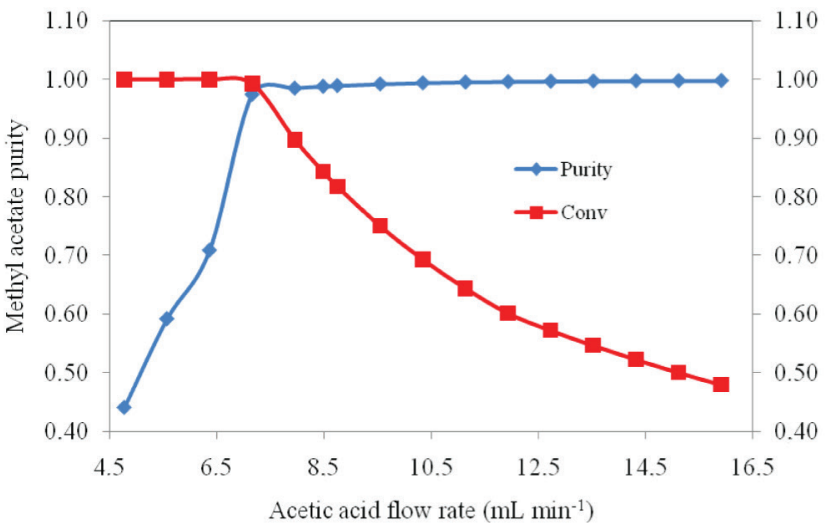

Fig. 11 - Effect of acetic acid feed flow rate on the methyl acetate purity and acetic acid conversion

was almost constant. After $8.5 \mathrm{~mL} \mathrm{~min}^{-1}$, a further increase in flow rate caused the increase in conversion but the methyl acetate purity slightly decreased. The main reason being that the excess methanol caused high conversion but it entered into the rectifying zone and collected in the distillate. Therefore, the purity of methyl acetate had decreased.

\section{Conclusions}

Reactive distillation is proven to be an efficient process for the esterification reactions. The non-ideal pseudo-homogeneous kinetic model is successfully applied for the reactive distillation process. The performance of reactive distillation for the esterification of acetic acid and methanol to produce methyl acetate is influenced by reboiler temperature, reflux ratio, bottom flow rate, feed flow rate of reactants, and feed temperatures of the reactants. The maximum conversion of acetic acid was achieved by catalytic reactive distillation obtained at reflux ratio of 2 . The effect of the feed flow rate of acetic acid and methanol on the conversion of acetic acid is greater. The equilibrium stage wise model predictions have been compared with experimental results, and it was found that they are in good agreement. From the sensitivity analyses, it was found that the bottom flow rate, feed temperatures, and flow rates had a greater effect on the conversion of acetic acid as well as on the purity of methyl acetate in the distillate.

\section{Nomenclature}

$d$ - distillate flow rate, mol L $\mathrm{L}^{-1}$

$f$ - feed flow rate, $\mathrm{mol} \mathrm{h}^{-1}$

$f_{A}$ - acetic acid feed flow rate, mol L ${ }^{-1}$

$h$ - enthalpy, $\mathrm{J} \mathrm{mol}^{-1}$

$l$ - liquid flow rate, $\mathrm{mol} \mathrm{h}^{-1}$

$\mathrm{N}$ - total number of segments

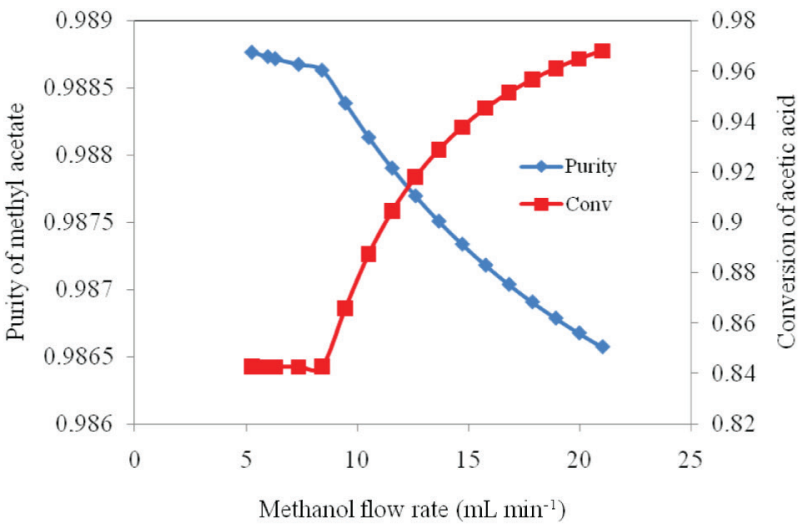

Fig. 12 - Effect of methanol feed flow rate on the methyl acetate purity and acetic acid conversion

$p \quad$ - saturation pressure, $\mathrm{Pa}$

$p_{\text {total }}-$ total pressure, $\mathrm{Pa}$

$q_{C}$ - condenser heat duty, $\mathrm{W}$

$q_{R}$ - reboiler heat duty, $\mathrm{W}$

rxn - reaction rate, $\mathrm{mol} \mathrm{L}^{-1} \mathrm{~h}^{-1}$

$w$ - bottoms flow rate, $\mathrm{g} \mathrm{min}^{-1}$

$x \quad-$ liquid mole fraction

$y \quad-$ vapor mole fraction

$x_{A w}$ - mole fraction of acetic acid in bottoms

$x_{A d}$ - mole fraction of acetic acid in distillate

$x_{A f}-$ mole fraction of acetic acid in feed

$X_{A}-$ acetic acid conversion

$v \quad-$ vapor flow rate, $\mathrm{mol} \mathrm{h}^{-1}$

$z \quad-$ feed composition

\section{Subscripts}

i - component index

j $\quad-$ segment(stage) index

\section{Superscripts}

f - feed

1 - liquid phase

$\mathrm{v}$ - vapor phase

\section{References}

1. Taylor, R., Krishna, R., Modeling reactive distillation, Chem. Eng. Sci. 55 (2000) 5183. doi: https://doi.org/10.1016/S0009-2509(00)00120-2

2. Wang, H., Pang, L., Yang, C., Liu, Y., Production of glycerol via reactive distillation and extractive distillation: An experimental study, Chin. J. Chem. Eng. 23 (2015) 1469. doi: https://doi.org/10.1016/j.cjche.2015.06.011

3. Tian, H., Zhao, S., Zheng, H., Haung, Z., Optimization of coproduction of ethyl acetate and butyl acetate by reactive distillation, Chin. J. Chem. Eng. 23 (2015) 667. doi: https://doi.org/10.1016/j.cjche.2014.12.007 
4. Kloker, M., Kenig, E. Y., Gorak, A., Markusse, A. P., Kwant, $G$., Moritz, $P$., Investigation of different column configurations for the ethyl acetate synthesis via reactive distillation, Chem. Eng. Proc. 43 (2004) 791. doi: https://doi.org/10.1016/S0255-2701(03)00084-9

5. Sandesh, K., Jagadeeshbabu, P. E., Math, S., Saidutta, M. $B$., Reactive distillation using an ion exchange catalyst: Experimental and simulation studies for the production of methyl acetate, Ind. Eng. Chem. Res. 52 (2013) 6984. doi: https://doi.org/10.1021/ie3029174

6. Yadav, G. D., Mehta, P. H., Heterogeneous catalysis in esterification reactions, Ind. Eng. Chem. Res. 33 (1994) 2198. doi: https://doi.org/10.1021/ie00033a025

7. Song, W., Venimadhavan, G., Manning, J. M., Malone, M. F., Doherty, M. F., Measurement of residue curve maps and heterogeneous kinetics in methyl acetate synthesis, Ind. Eng. Chem. Res. 37 (1998) 1917. doi: https://doi.org/10.1021/ie9708790

8. Agreda, V. H., Partin, L. R., Heiss, W. H., High purity methyl acetate via reactive distillation, Chem. Eng. Prog. 86 (2) (1990) 40.

9. Bessling, B., Loning, J., Ohligschlager, A., Schembecker, G., Sundmacher, K., Investigation on the synthesis of meth$\mathrm{yl}$ acetate in a heterogeneous reactive distillation process, Chem. Eng. Tech. 21 (1998) 393. doi: https://doi.org/10.1002/(SICI)1521-4125(199805)21:5< 393::AID-CEAT393>3.0.CO; 2-9

10. Popken, T., Steinigeweg, S., Gmehling, J., Synthesis and hydrolysis of methyl acetate by reactive distillation using structured catalytic packings: Experiments and simulation, Ind. Eng. Chem. Res. 40 (2001) 1566. doi: https://doi.org/10.1021/ie0007419

11. Kreul, L. U., Gorak, A., Dittrich, C., Barton, P. I., Dynamic catalytic distillation: Advanced simulation and experimental validation, Comp. Chem. Eng. 22 (1998) S371. doi: https://doi.org/10.1016/S0098-1354(98)00077-5
12. Gorak, A., Hoffmann, A., Catalytic distillation in structured packings: Methyl acetate synthesis, AIChE. J. 47 (2001) 1067. doi: https://doi.org/10.1002/aic.690470513

13. Mekala, M., Goli, V. R., Kinetics of esterification of methanol with acetic acid using mineral homogeneous acid catalyst, Chin. J. Chem. Eng. 23 (2015) 100. doi: https://doi.org/10.1016/j.cjche.2013.08.002

14. Mekala, M., Thamida, S. K., Goli, V. R., Pore diffusion model to predict the kinetics of heterogeneous catalytic esterification of acetic acid and methanol, Chem. Eng. Sci. 104 (2013) 565. doi: https://doi.org/10.1016/j.ces.2013.09.039

15. Mekala, M., Goli, V. R., Comparative kinetics of esterification of methanol-acetic acid in the presence of liquid and solid catalysts, Asia-Pacific. J. Chem. Eng. 9 (2014) 791. doi: https://doi.org/10.1002/apj.1798

16. Mekala, M., Goli, V. R., Kinetic study of esterification of acetic acid with methanol over Indion 190 acidic solid catalyst, Kin. Cat. 54 (2015) 419.

17. Mekala, M., Goli, V. R., Kinetics of esterification of acetic acid and methanol using Amberlyst 36 cation-exchange resin solid catalyst, Prog. Reac. Kin. Mech. 40 (2015) 367. doi: https://doi.org/10.3184/146867815X14413752286146

18. Peng, J., Lextrait, S., Edgar, T. F., Eldrige, R. B., A comparison of steady-state equilibrium and rate-based models for packed reactive distillation columns, Ind. Eng. Chem. Res. 41 (2002) 2735. doi: https://doi.org/10.1021/ie010969b

19. Mallaiah, M., Venkat Reddy, G., Optimization studies on a continuous catalytic reactive distillation column for methyl acetate production with surface methodology, J. Taiwan Inst. Chem. Eng. 69 (2016) 25. doi: https://doi.org/10.1016/j.jtice.2016.10.007 